\title{
Grundzüge einer neuen Bestimmungsmethode der Kohlensäure in der Luft
}

\author{
(vorläufige Mittheilung) \\ von \\ Oberstabsarzt Prof. Dr. Fl. Kratschmer \\ und \\ Regimentsarzt Dr. E. Wiener.
}

Aus dem chemischen Laboratorium des k. u. k. Militär-Sanitäts-Comité.

(Vorgelegt in der Sitzung am 12. Juli 1894.)

Die hohe Empfindlichkeit des von $\mathrm{Luck}^{1}$ empfohlenen Phenolphthaleïn als Indicator bei der Acidimetrie und Alkalimetrie unter gewissen Bedingungen ist bekannt.

Die Gegenwart kleinster Mengen von alkalischen Erden und fixen Alkalien bei Ausschluss von Ammoniak wird durch dieses Reagens mit einem jähen Übergange von farblos zu purpurroth angezeigt.

Freie und sogenannte halbgebundene Kohlensäure wirken entfärbend.

Wir haben uns durch viele Versuche überzeugt, dass diese Reaction bei den fixen Alkalihydraten und -Carbonaten, sowie deren Gemischen genau quantitativ verläuft.

Wir haben diese Beobachtungen bis zur Darstellung einer Methode verfolgt, den Kohlensäuregehalt der Luft genau quantitativ zu bestimmen.

Es wurden Lösungen von Natriumcarbonat einerseits und von Schwefelsäure anderseits bereitet, welche pro Kubikcentimeter genau $1 \mathrm{mg}$ Kohlensäure entsprachen.

1 Fresenius, Zeitschr. fïr analyt. Chemie, 1887, S. 332. 
Bei der Titrirung der Natriumcarbonatlösung unter Verwendung des Phenolphthaleïn als Indicator mit der zugehörigen Schwefelsäure wird bei gewöhnlicher Temperatur bis zur Entfärbung genau die halbe, beim anhaltenden Kochen genau die ganze Portion der Schwefelsäure aufgebraucht.

Die Reaction erfolgt demnach auch in so verdünnten Lösungen zuerst nach der Gleichung

$$
2 \mathrm{CO}_{3} \mathrm{Na}_{2}+\mathrm{H}_{2} \mathrm{SO}_{4}=2 \mathrm{CO}_{3} \mathrm{NaH}+\mathrm{Na}_{2} \mathrm{SO}_{4},
$$

wobei die jetzt halb gebundene Kohlensäure entfärbend wirkt; sodann beim anhaltenden Kochen nach der Gleichung

$$
2 \mathrm{CO}_{3} \mathrm{NaH}+\mathrm{H}_{2} \mathrm{SO}_{4}=2 \mathrm{CO}_{2}+\mathrm{H}_{2} \mathrm{O}+\mathrm{Na}_{2} \mathrm{SO}_{4},
$$

wobei nunmehr die Spur überschüssiger Schwefelsäure die Entfärbung herbeiführt.

Bei der Titrirung von Gemischen aus Natriumhydrat und -Carbonat von hier in Betracht kommenden Concentrationen mittelst entsprechend verdünnter Schwefelsäure besteht der gleiche Verlauf und die gleiche Empfindlichkeit der Reaction.

Jede auf gewöhnlichem Wege erzeugte Natronlauge enthält eine gewisse Menge von Natriumcarbonat. Das Mengenverhältniss beider lässt sich mittelst des Phenolphthaleïn als Indicator genauestens feststellen.

Wird eine solche Natronlauge zur Absorption von Kohlensäure verwendet, so muss die Differenz zwischen dem Verbrauche an Schwefelsäure zur Titrirung bei gewöhnlicher Temperatur vor und nach der Kohlensäureabsorption genau der Hälfte der absorbirten Kohlensäure entsprechen.

Daraus folgt, dass Lösungen von Kalium- oder Natriumhydrat von der früher angegebenen Concentration auch bei einem geringen Gehalte an bereits rorgebildetem Carbonat zur genauen Ermittlung der Kohlensäure verwendbar sein müssen, wenn die einzige Bedingung erfüllt wird, dass sie aus dem bei dem Versuche gebotenen Luftquantum die Kohlensäure vollständig aufnehmen.

Dieser Bedingung wird, wie wir uns überzeugt haben, genügt, wenn entsprechende Mengen der obigen Alkalihydratlösung in der verschlossenen Flasche, worin sich die auf den 
Kohlensäuregehalt $\mathrm{zu}$ untersuchende Luft befindet, etwa eine halbe Stunde anhaltend herumgetrieben werden.

Behufs directer Erprobung des Verfahrens wurden in eine mit kohlensäurefreier Luft gefüllte Flasche von farblosem Glase unter den entsprechenden Cautelen $100-200 \mathrm{~cm}^{3}$ der Alkalihydratlösung, sodann verschlossene, genau calibrirte Glasgefässchen, welche mit reiner Kohlensäure beschickt waren, eingetragen Beim Schütteln der Flasche zersplitterte das Glasröhrchen und dessen Inhalt wurde von der Alkalihydratlösung aufgenommen.

Gleiche Quantitäten der Alkalihydratlösung wurden in toto vor und nach der Absorption der Kohlensäure mit Schwefelsäure, von welcher $1 \mathrm{~cm}^{3} 1 \mathrm{mg}$ Kohlensäure entsprach, titrirt.

Die jeweilig verwendeten Volumina der Kohlensäure sind mit Berücksichtigung der Temperatur und des Barometerstandes in Gewichtsgrössen umgerechnet.

Die Ergebnisse dieser Prüfung erscheinen befriedigend, wie einige Beispiele lehren.

\begin{tabular}{|c|c|}
\hline \multicolumn{2}{|c|}{ Kohlensäure } \\
\hline eingetragene & gefundene \\
\hline $16.09 \mathrm{mg}$ & $16.00 \mathrm{mg}$ \\
\hline $11 \cdot 17$ & $11 \cdot 05$ \\
\hline $16 \cdot 18$ & $16 \cdot 08$ \\
\hline $15 \cdot 60$ & $15 \cdot 43$ \\
\hline $44 \cdot 47$ & $45 \cdot 40$ \\
\hline
\end{tabular}

Darnach gestaltet sich das Verfahren für die Kohlensäurebestimmung in der Luft folgendermassen:

Eine genau calibrirte Flasche aus farblosem Glase wird mit der Luft, deren Kohlensäuregehalt zu ermitteln ist, in bekannter Weise beschickt.

In diese Flasche werden $100-200 \mathrm{~cm}^{3}$ der Alkalihydratlösung, deren Verhältniss zu einer Schwefelsäure, von welcher $1 \mathrm{~cm}^{3}$ genau $1 \mathrm{mg}$ Kohlensäure entspricht, unmittelbar vor dem Versuche festgestellt ist, eingetragen. Es ist zweckmässig, in die Flasche auch Glasperlen oder Glasscherben einzubringen; die Absorption der Kohlensäure beim Schütteln der ver- 
schlossenen Flasche wird durch die grosse Vertheilung der Alkalihydratlösung mittelst der Glassplitter erheblich gefördert.

Nach etwa halbstündigem Schütteln wird die Flasche gelüftet und, nachdem einige Tropfen der Phenolphthaleïnlösung eingebracht sind, möglichst rasch mit der Schwefelsäure bis zur Entfärbung titrirt.

Betrug die Menge der bis zur Endreaction erforderlichen Schwefelsäure auf das gleiche Quantum der Alkalihydratlösung vor der Kohlensäureabsorption $a$, nach derselben $b$, so ist $(a-b) \times 2$ gleich der Menge der in der Flaschenluft enthaltenen Kohlensäure in Milligrammen.

Blochmann ${ }^{1}$ und $\mathrm{Ballo}^{2}$ haben die Verwendung des Phenolphthaleïn als Indicator zu einer annäherungsweisen Bestimmung der Kohlensäure in der Luft zum Gegenstande von Untersuchungen gemacht, jedoch in anderer Weise, als es hier dargestellt ist.

1 Ber. der deutsch. chem. Ges., 1884, S. 1017, und Frese ni us, Zeitschr. für analyt. Chem., 1884, S. 333.

2 Ber. der deutsch. chem. Ges. 1884, S. 1097. 